\title{
Phytoplankton Orientation in a Turbulent Ocean: A Microscale Perspective
}

\author{
G. Basterretxea ${ }^{1 *}$, J. S. Font-Muñoz ${ }^{2,3 *}$ and I. Tuval1,4* \\ ' Department of Marine Ecology, Mediterranean Institute for Advanced Studies, University of the Balearic Islands and \\ Spanish National Research Council, Esporles, Spain, ${ }^{2}$ Université de Brest - Université de Bretagne Occidentale/Centre \\ National de la Recherche Scientifique/French Research Institute for Exploitation of the Sea/Institut de Recherche pour le \\ Développement, Brest, France, ${ }^{3}$ French Research Institute for Exploitation of the Sea, French Institute for Sea Research, \\ Dynamiques des Ecosystèmes Côtiers Laboratoire d'Ecologie Pélagique, Plouzané, France, ${ }^{4}$ Department of Physics, \\ University of the Balearic Islands, Palma, Spain
}

Phytoplankton are by definition autotrophic microorganisms that passively drift with fluid motion. Accordingly, the traditional view of a turbulence-homogenized phytoplankton distribution in the ocean, where cells randomly organize and interact, is deeply rooted in biological oceanography studies. However, increasing understanding of microscopic processes in the ocean is revealing a world of microscale patterns resulting from cell behaviors and fluid-cell interactions that challenges this vision. Autotrophic cells have developed active (i.e., flagella) and passive (i.e., morphological structures and vesicles) motility mechanisms that allow them different degrees of spatial control. Their complex interaction with the ocean physicochemical landscape commonly results in small-scale spatial heterogeneities and non-isotropic orientations that can strongly influence ecosystem level processes. Cell orientation, in particular, is fundamental for key biological functions such as sensing, metabolism, locomotion, chain formation, or sexual reproduction. Moreover, preferential alignment of elongated cells can modulate the propagation of light through the ocean and is fundamental for accurate interpretation of remote sensing data. Innovative observational and experimental techniques (e.g., in situ holography, laser diffractometry, etc.) allowing the subtle analysis of cell-fluid interactions are revealing that, at the microscopic level, organisms present well defined orientation and interaction patterns under prevalent conditions in the sea. Thus, the interplay of biology, fluid dynamics, and optics may shape, by means of anisotropic cell distributions, pivotal cross-scale aspects of phytoplankton ecology.

Keywords: phytoplankton, microscale, turbulence, orientation, shear

\section{INTRODUCTION}

Each process occurring in the marine environment has an associated fundamental temporal and spatial scale, but cross-scale links exist conforming the full complexity of ocean ecosystem dynamics. For a long time, the microscale structure of the ocean $(<1 \mathrm{~mm})$, which is relevant to understanding many phytoplankton related processes, has been overlooked in the framework of biological oceanography. There are technical and conceptual historical reasons for this dissociation between studies of the seemingly chaotic microscopic habitat where algal cells grow and interact with their congeners and with other organisms, and research on larger scale processes determining 
the fate of marine phytoplankton. In this review, we contribute to conciliate these two worlds, with the conviction that understanding the interaction among processes occurring at the micro- and macroscopic scales can enhance our understanding of phytoplankton and ocean ecosystem dynamics. Here, we particularly aim at exploring the importance of preferential cell orientation in the ocean; a ubiquitous example of a microscale process for which large scale implications are anticipated.

\section{A BRIEF HISTORICAL REVIEW}

Early studies assumed that pelagic phytoplankton spent most of their life cycle freely suspended in the water column and that, despite the motile ability of some species, movements were too weak to overcome fluid motion. Pioneering botanist and zoologist Hensen (1887) inferred that, if the environment was uniform, plankton should be uniformly distributed freely drifting passively in the sea. Implicitly, plankton were believed to be poorly structured and organized at small scales where microbial organisms were randomly oriented by shear and turbulence. Only conspicuous larger scale space and time variations generally associated with changes in hydrographic properties and seasonality were recognized. Highly influential Hensen's theories were eagerly confronted by contemporary studies by Haeckel (1891) who defended an irregular distribution of plankton both in time and space. Although Haeckels's criticisms were initially overlooked, subsequent investigations revealed non-homogeneous organism distributions that early researchers ascribed to small scale fluid patterns driven by unequal heat distribution (Sachs, 1876). To the eyes of the microscopist, cells often showed active orientation and movement in a definite direction (Schwarz, 1884) and field observations revealed that some phytoplankton species even presented marked diurnal and seasonal migration patterns, as well as aggregation behavior (Wager, 1910). Nevertheless, the idea of homogeneously and isotropically mixed plankton organisms persisted until the 50s when new concepts and theories arose showing the importance of small-scale plankton processes (Barnes and Marshall, 1951; Bainbridge, 1957; Cassie, 1959, 1963).

The mid-20th century was an important epoch for the development of physical and biological oceanography. Advances were made by introducing mathematical foundations in the study of plankton ecology which opened new possibilities for the understanding of the fundamental processes controlling plankton (see Russel, 1950). In this context, Harvey (1942) analyzed the interactions between different components of plankton (phytoand zooplankton) and the relationships between these and the surrounding water. Riley (1942) and Riley et al. (1949) described the impact of water column stability on spring blooms, Sverdrup (1953) postulated the conditions for vernal phytoplankton blooms and Margalef $(1967,1978)$ provided a holistic perspective to phytoplankton organization. Also, a conceptual framework was proposed analyzing plankton variability over various spatial scales together with the physical factors contributing to this variation (Haury et al., 1978). These and other studies made evident that the apparent uniformity of the oceans was simply "an illusion generated by the original need for widely spaced sampling both horizontally and vertically" (Steele, 1959). Small scale heterogeneities and individual interactions in which cell orientation plays a fundamental role were still ignored but as part of these simplified large biological compartments.

With the advent of new continuously sampling instrumentation like fluorometers (Lorenzen, 1966) and particle counters (Sheldon et al., 1972), marine scientists were able to address the patterns of spatial variability of phytoplankton and to determine its structure. These features where crucial for the understanding of its role as a food source for marine life (see Steele, 1978 and review by Vance and Doel, 2010). The ocean was now conceived as a mixture of process spanning from length scales of centimeters to thousands of kilometers and associated timescales ranging from seconds to centuries (Stommel, 1963; Haury et al., 1978). Progress was made in the measurements of turbulence in the ocean and in the development of a turbulence theory that was rapidly assimilated into physical oceanography (Grant et al., 1962; Levich, 1962). Nevertheless, a preconception that phytoplankton behaved like passive particles immersed in the flow field and, thus, their distribution was driven by turbulence, was the general consensus (see Platt, 1972, 1978). The "red noise" power spectra for physical and biological properties depicted from continuous underway measurements demonstrated that the effects of physical forces dissipated effectively during the cascade of energy transfer to scales on the order of meters (Powell et al., 1975; Denman and Platt, 1976). Spatial scales below this level were seldom considered either because of lack of technology for the observation of the sea at these scales, or because adding sampling detail was assumed irrelevant for the scientific challenges of the time (i.e., seasonal variations, mesoscale processes, regional the productivity of the ocean). As a consequence, biologists and ecologists observing the complexity of the microscopic world (mostly restricted to taxonomists and microbiologists) diverged in aims from a rapidly developing community of biological oceanographers interested in the more evident and predictable changes in phytoplankton at larger scales.

It was not until the last quarter of the century, with the focus in microbial motility, feeding mechanisms, and encounter rates, that interest on understanding phytoplankton related processes at the microscale, including cell orientation, was renewed (Holwill, 1974; Lighthill, 1976; Lehman and Scavia, 1982; Rothschild and Osborn, 1988; Fenchel, 1993; Kiørboe, 1993). The study of patchiness acquired importance because it affected cell densities and thus regulated encounter rates among organisms. It became apparent that interactions were not only ruled by mixing rates. Also, it was speculated that small planktivores survived where their food rations appeared too low by making use of adequate food patches too small to detect (Owen, 1989). Improved bio-optical instrumentation showed the existence of persistent thin layers with high phytoplankton abundance spanning over large horizontal distances (e.g., Cowles et al., 1998; Dekshenieks et al., 2001). While estimates of many microscale processes (e.g., encounter rates, competition) were implicitly based on a random distribution of plankton, a number of key works in the field of microbiology showed a 
rich physical and biochemical heterogeneity at submillimetric scales (Derenbach et al., 1979; Gregg, 1980); however, recent studies have shown that these submillimetric patches often may represent single large phytoplankton cells, chains, or aggregates (Doubell et al., 2014). Biological studies at the microscale remained considered a separate discipline and were seldom integrated in mainstream oceanography perspectives. This led to some long-standing ecological misconceptions. For example, it is remarkable that the concept that phytoplankton orientations and spatial distributions along with environmental parameters such as heat and nutrients are passively homogenized by turbulence has persisted through time (e.g., Siegel, 1998; Currie and Roff, 2006). This inherited scale-biased vision in which small scale processes average out at larger scales and can therefore be considered irrelevant, contrasts with the viewpoint of other disciplines, like physics, where the continuum between the subatomic processes and astrophysics and the necessity of understanding all spatial scales is well established. It also contraposes ecological theories about system behavior based on hierarchical interactions among processes at different scales (i.e., self-organization or resilience; Holling, 1992; Rietkerk et al., 2004).

\section{UPSCALING EFFECTS OF THE MICROSCOPIC WORLD}

Microscale and single cells studies are nowadays acknowledged as the cutting-edge of plankton research (e.g., Seymour et al., 2010; Rusconi et al., 2014). The concept that plankton displaces where the water transports it remains broadly valid and turbulence is the dominant physical process redistributing small organisms. But, as we begin to understand the processes occurring at the smaller scales, the importance of interfacing this microhabitat with larger scale dynamics is evidenced (Prairie et al., 2012). As in other ecological fields, to fully understand phytoplankton dynamics we must decipher first how information is transferred between scales: from fine to broad, and vice versa (Levin, 1992).

The oceanic flow fields and their interaction with phytoplankton entail a nearly continuous spectrum of motions and associated processes which range from global scale circulation to the smaller molecular adjustments and from ecosystems to individual cells (Figure 1). The appearance and effects of flow change dramatically as one moves from the human scale, at which our intuition is trained, to the microscale, at which microorganisms experience flow (Kiørboe, 2008; Wheeler et al., 2019). Because the majority of phytoplankton are smaller than the smallest eddy size by one or two orders in magnitude, processes affecting individual cells develop in the viscous non-inertial realm where they displace with no turbulent drag (Purcell, 1977). This microscopic environment may be envisioned as a universe of viscous packets that are transported rapidly through a turbulence field (Reynolds, 2006). At this scale, turbulent energy dissipates as heat while water motion can be characterized as laminar shear. Phytoplankton experience turbulence as an instantaneous, linearly varying fluid velocity across the cell body (Jumars et al., 2009; Barry et al., 2015) and

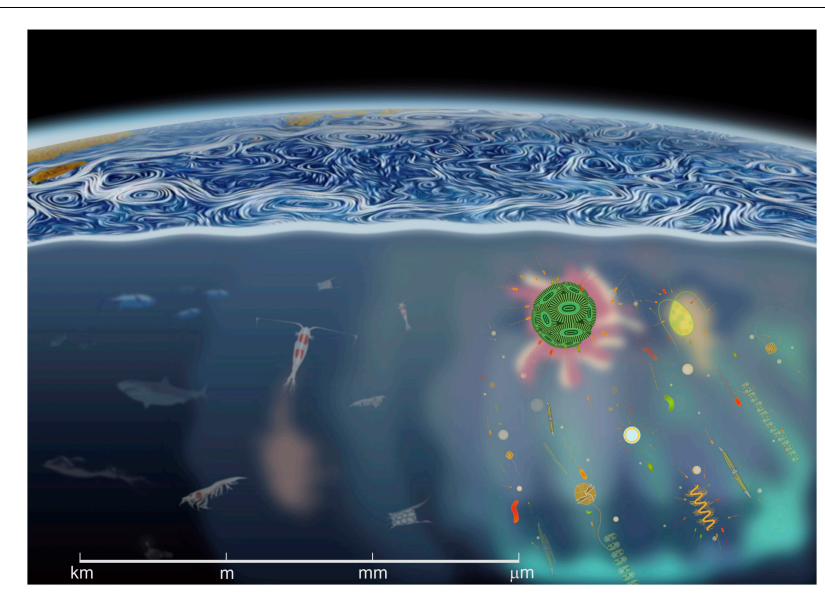

FIGURE 1 | A cross-scale view of the ocean spanning from linear gradients and microscale interactions (right), to top predators and mammals and regional circulation patterns (left and top). The scale at the bottom provides a reference of the spatial dimension in which the interactions between distinct organisms occur. The linear microbial landscape is embedded in a world of turbulent motions and progressively larger swirls.

interactions with the surrounding environment are effective at defining anisotropic organism orientations.

Contrarily to common view, stirring strengthens linear gradients at the microscale level therefore generating a landscape full of gradients, as determined by the Bachelor scale. Variability in cell microhabitats is fundamental to the way organisms exploit the resources and interact with other organisms, either mates, parasites, or predators. Considering that most pelagic environments are extremely dilute, insofar as the supply of the spectrum of the cells' chemical requirements is concerned (Reynolds, 1997), this heterogeneity provides opportunity for coexistence of species despite their differential fitness, therefore favoring diversity.

Whenever individual cells are important, the linear world under the Kolmogorov scale (Kolmogorov, 1941, 1962) must be considered. According to Stocker (2012), the spatial scale that is relevant for a single cell depends on behavior and time. At day scales, small non-motile cells restrict their universe to a micrometric environment defined by their Brownian motion, whereas swimming organisms evolve in a horizon of centimeters. It is the behavior of phytoplankton relative to its most immediate fluid layer and the transport of this microenvironment within larger scale flows which determines some relevant patterns of phytoplankton (Figure 2). Movement is a necessity for phytoplankton cells that would otherwise become rapidly nutrient limited by the inefficient molecular diffusion. If the phytoplankton cell is sinking or is able to move, the microzone of nutrient-depleted water surrounding the cell will be replaced faster than if the cell remains motionless; in effect the steepness of the nutrient gradient and, hence, the nutrient uptake rate will increase due to this advective transport of nutrients toward the cell surface.

Some motile phytoplankton can vertically orient and swim over tens of meters of the water column per day vertically varying 


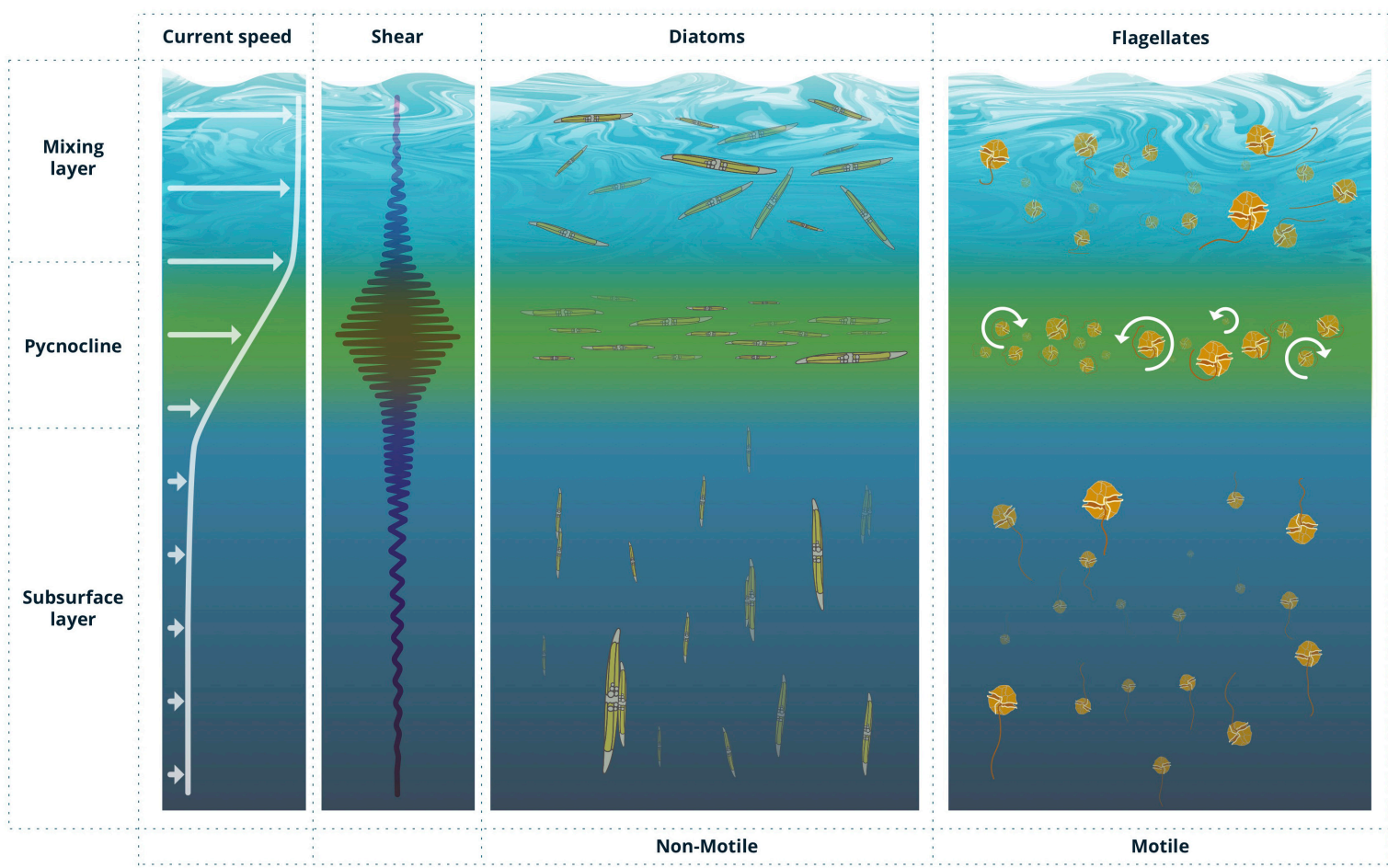

FIGURE 2 | Idealized profiles of current speed and shear in the ocean and corresponding preferential cell orientation of non-motile and motile phytoplankton cells, including the formation of thin layers, in response to varying shear conditions.

the biomass distribution (e.g., Jeong et al., 2015). Likewise, nonmotile phytoplankton -e.g., some diatom and cyanobacteria species- orient in hydrodynamically favorable directions to displace over large distances (e.g., Eppley et al., 1968) by either positively or negatively varying their buoyancy through different mechanisms such as gas vesicles, lipid storage, the exchange of heavy ions with their surroundings or by forming chains that modify their sinking rates (Gross and Zheuten, 1948; Anderson and Sweeney, 1978; Walsby, 1994). These directionally oriented patterns often respond to collective behaviors common to many planktonic organisms, which favor cell to cell interactions at the population level and may produce far reaching effects at larger scales, for instance by contributing to the vertical transport of carbon and nutrients (e.g., Cullen and Horrigan, 1981; Schofield et al., 2006; Hall and Paerl, 2011). Physical coagulation, facilitated by secretion of viscous extracellular polysaccharides, is a fundamental part of marine snow formation and carbon recycling processes (Passow, 2002).

\section{PHYTOPLANKTON ORIENTATION IN THE SEA}

Cell orientation, widely believed to be homogenized by the effect of turbulence, is a prime example of erroneous preconceptions in phytoplankton ecology. In fact, and on the contrary, the interaction between cell shape, motility, and fluid flows establishes a plethora of non-uniform orientational distributions.
These, in turn, affect a rich variety of key biological functions epitomizing the relevance of mechanisms occurring at the scale of microns to centimeters for the correct interpretation of larger scale processes. These include sensing, nutrient uptake, parasite and predator avoidance, competition for resources, reproduction, the quest for optimal light conditions for growth or aggregation of phytoplankton into marine snow (Eppley et al., 1968; Smayda, 1980; Denny, 1993; Reynolds, 2006; Kiørboe, 2008; Burd and Jackson, 2009).

For motile organisms, whose orientation is mainly driven by body asymmetry that favors directed swimming, preferential orientation occurs in a variety of forms: as active responses to locally anisotropic environmental stimuli, such as photoor chemotaxis, and as passive responses to the incessantly moving fluid environment (e.g., gyro- or rheotaxis). These oriented responses or "taxes" are the result of the necessity of the organism to react to specific gradients or stimuli and are greatly facilitated by cell motility. Even though it is energetically demanding, motility is advantageous in a world where resources (i.e., nutrients) are heterogeneously distributed (Stocker et al., 2008). The majority of the phytoplankton classes are flagellated and, therefore, motile. Since velocities generated by flagellar movement (50-500 $\mu \mathrm{m} \mathrm{s}^{-1}$; Sournia, 1982 and references therein) are commonly larger than the Kolmogorov velocity microscale $^{1}, \quad V_{K}=(\nu \varepsilon)^{1 / 4}$, motility allows for a reasonable

\footnotetext{
${ }^{1}$ Where $\nu$ is the kinematic viscosity of the water $\left(\sim 10^{-6} \mathrm{~m}^{2} \mathrm{~s}^{-1}\right.$ for sea water $)$ and $\varepsilon$ is the mean dissipation rate of turbulent kinetic energy $\left(\varepsilon \approx 10^{-10}\right.$ to $\left.10^{-5} \mathrm{~m}^{2} \mathrm{~s}^{3}\right)$.
} 
control of orientation. Cells move to new locations to seek more favorable environments or to interact with other organisms.

Among the variety of phytoplankton response cues (hydrodynamics, nutrient availability, predator and/or parasite avoidance, etc.), most commonly observed taxes are the positive phototaxis triggering migration to the sea surface during daylight hours and negative gravitaxis driving cell descent at night. This oriented swimming determines, for instance, marked circadian patterns in several dinoflagellate species. However, most importantly, movement also allows phytoplankton cells to cross unfavorable microenvironments and to access microscale nutrient maxima (Guasto et al., 2012).

Studies on microorganism motility under distinct flow conditions further evidence how coupling between swimming and fluid flow can result in non-random cell orientations, and consequently, non-uniform cell accumulation. Paradigmatic examples include laboratory experiments and modeling on gyrotaxis, where local shear flow couples to motility to induce cell focusing in localized streams (Kessler, 1985; Pedley and Kessler, 1992), dynamic aggregation regimes (Durham et al., 2011) and intense patchiness in turbulent flows far exceeding that of randomly distributed, non-motile populations (Durham et al., 2013); or rheotaxis, where swimming cells (whether bacteria, heterotrophs, sperm cells, or phytoplankton) reorient with respect to gradients in the flow velocity to successfully migrate in the local upstream direction (Marcos et al., 2012; Bukatin et al., 2015; Mathijssen et al., 2019).

Likewise, vertical gradients in horizontal velocity in the water column $(S=\partial \mathrm{u} / \partial \mathrm{z})$ can disrupt vertical migration of gyrotactic phytoplankton. When vertically swimming cells encounter regions of strong horizontal shear flows, their orientation can be dramatically altered, causing them to tumble continuously and triggering sharply peaked cell accumulations in localized layers and regions of enhanced shear (Durham et al., 2009; Durham and Stocker, 2012). This trapping effect arising from shear flow has been proposed to be a plausible mechanism for the formation of the frequently observed thin layers of phytoplankton in aquatic systems (Figure 2).

Non-motile phytoplankton can also exhibit preferential orientation and movement under the influence of gravity, at least in the case of the larger microplanktonic cells such as diatoms. Cell orientation influences displacement trajectories, sinking velocities and cell concentrations. A growing number of studies have advanced our understanding of the translation, rotation, and orientation of dilute suspensions of small spheroids and fibers in turbulence, highlighting the rich dynamics of interactions (Metzger et al., 2005; Botte et al., 2013). Insight on the behavior of particles in these flow regimes mainly emanates from experiments and theory developed for dilute suspensions of fibers and spheroids (see Voth and Soldati, 2017) yet, most studies in this field corresponds to inertial particles above Kolmogorov length scales and, therefore, not directly transposable to phytoplankton. The interplay between cell buoyancy regulated displacements and their entrainment by turbulence leads, under general conditions, to even more acute non-homogeneous distributions (Arrieta et al., 2015; Borgnino et al., 2019) and greater social complexity amongst planktonic species is predicted in regions of large shear (Breier et al., 2018; Uppal and Vural, 2018).

The fact that shear generates changes in velocity in the proximity of the organisms results in forces and torques that depend on cell orientation. Torque favors the rotation of cells with an angular speed which leads to preferential alignment with the flow. Rotation is proportional to the velocity gradient and depends on shape (Barry et al., 2015). Two different behaviors can be approximated depending on cell shape; prolate shapes (cells with the apical to transapical ratio $\lambda>1$ ) that approximate the rod-like morphology of pennate diatoms and oblate shapes $(\lambda<1)$, similar to disk-shaped centric diatoms. Non-spherical cells describe periodic orbits as they sink in Couette (laminar) flows. According to Jeffery (1922), prolate cells tend to set their apical axis perpendicular to the plane of the undisturbed fluid motion describing steady periodic orbits. Oblate cells tend to set themselves with an equatorial diameter perpendicular to the plane of undisturbed motion of the fluid while rotating periodic but not steadily. In unsteady shear and turbulent flows, this reorientation dynamics becomes far more complex.

Certain cells can counteract rotation by actively varying the distribution of mass inside the cell or passively using morphological structures such as with protuberances and spines, or certain body shapes. Others are able to form chains and aggregations increasing even further their vertical displacements (Lovecchio et al., 2019). The evolutive solutions to this problem have resulted in a remarkable diversity of phytoplankton morphologies. For example, spines in non-motile phytoplankton have been suggested to decrease settling rates by enhancing drag and elongated morphologies may alter the organisms' orientational distribution in flow. These structures may be biologically important since they produce cell tumbling that increases cell encounter probabilities with nutrient and infochemical micro-patches and with neighboring cells and grazers (Karp-Boss et al., 1996; Kiørboe, 2008). In contrast, in the presence of intense shear, cells are preferentially aligned with the flow which limits their ability to migrate in other (e.g., perpendicular to the flow) directions, inexorably producing cell accumulations (see Figure 2). Shear induced preferential orientation of sinking spheroidal cells also drift them out of their prominently vertical motion to oversample downwelling regions of a turbulent flow which affects their average settling speed and modulates their escape time to the deep ocean (Ruiz et al., 2004; Arrieta et al., 2015; Ardekani et al., 2017; Borgnino et al., 2019). Moreover, and under quiescent flow environments, the coupling between orientation and sinking drift direction induces large scale hydrodynamic instabilities (Koch and Shaqfeh, 1989), facilitating cell encounters even under dilute conditions (Font-Muñoz et al., 2019).

Patterns of preferential orientation of motile and nonmotile phytoplankton has been by now amply shown in laboratory studies (e.g., Karp-Boss and Jumars, 1998; KarpBoss et al., 2000; Guasto et al., 2012). However, and despite noticeable technological progress over the last decades, direct observations of phytoplankton cells in their natural environment are still scarce. Most evidences of preferential cell orientation in the ocean have been obtained using digital holography. 
Talapatra et al. (2013), using a submersible holographic imaging system, analyzed diatom chain orientation and its relationship with mean shear rate in East Sound (WA, EEUU). More recently, also using holography, Nayak et al. (2018) observed preferential cell alignment at horizontal angles coinciding with regions of low velocity shear and weak turbulent dissipation rates. A different process related with preferential cell orientation of diatoms was inferred from in situ laser transmissometry (LISST-100 $\times$ ) by Font-Muñoz et al. (2019). In this case, a progressive increase in vertical cell alignment was observed under the pycnocline during a Pesudo-nitzschia sp. bloom. This preferential cell orientation was paralleled by an increase in the number of paired cells (up to $19 \%$ of the population) providing the first in situ link between orientational order and crucial intercellular interactions in the population dynamics of a cosmopolitan pennate diatom.

\section{CONCLUSION}

With the scientific advances carried out in the last century, our vision of marine phytoplankton and its interaction with the surrounding environment has expanded significantly. As we nosedive into the microscale, with the aid of new technology (and renew use of old technology), emerging insights reveal a highly structured, dynamic and organized realm. Phytoplankton interactions at this scale between congeners, competitors and with their immediate physico-chemical landscape, directly impinge on large scale oceanographic and ecosystem level processes.

Cell orientation, in particular, is a rarely assessed example of the relevance of these cross-scale interactions. Beyond its importance for key cell physiological processes, preferential cell

\section{REFERENCES}

Anderson, L. W. J., and Sweeney, B. M. (1978). Role of inorganic ions in controlling sedimentation rate of a marine centric diatom Ditylum Brightwelli. J. Phycol. 14, 204-214. doi: 10.1111/j.1529-8817.1978.tb02 450.x

Ardekani, M. N., Sardina, G., Brandt, L., Karp-Boss, L., Bearon, R., and Variano, E. (2017). Sedimentation of inertia-less prolate spheroids in homogenous isotropic turbulence with application to non-motile phytoplankton. J. Fluid Mech. 831, 655-674. doi: 10.1017/jfm.2017.670

Arrieta, J., Barreira, A., and Tuval, I. (2015). Microscale patches of nonmotile phytoplankton. Phys. Rev. Lett. 114:128102.

Bainbridge, R. (1957). The size, shape and density of marine phytoplankton concentrations. Biol. Rev. 32, 91-115. doi: 10.1111/j.1469-185x.1957.tb01577.x

Barnes, H., and Marshall, S. M. (1951). On the variability of replicate plankton samples and some application of 'contagious' series to the statistical distribution of catches over restricted periods. J. Mar. Biol. Assoc. U. K. 30, 233-263. doi: $10.1017 / \mathrm{s} 002531540001273 \mathrm{x}$

Barry, M. T., Rusconi, R., Guasto, J. S., and Stocker, R. (2015). Shear-induced orientational dynamics and spatial heterogeneity in suspensions of motile phytoplankton. J. R. Soc. Interface 12:20150791. doi: 10.1098/rsif.2015.0791

Borgnino, M., Arrieta, J., Boffetta, G., De Lillo, F., and Tuval, I. (2019). Turbulence induces clustering and segregation of non-motile, buoyancyregulating phytoplankton. J. R. Soc. Interface 16:20190324. doi: 10.1098/rsif. 2019.0324

Botte, V., D’Alcalaİ, M. R., and Montresor, M. (2013). Hydrodynamic interactions at low Reynolds number: an overlooked mechanism favouring diatom encounters. J. Plankton Res. 35, 914-918. doi: 10.1093/plankt/fbt033 orientation impacts the formation of thin phytoplankton layers, the absorption and transmission of light in the ocean (Marcos et al., 2011), its spectral characteristics (Goessling et al., 2018) and fundamental ecological interactions between organisms. Still, much remains to be explored both in terms of thorough field observations and detailed analysis of experimental conditions to fully appreciate the role of non-random phytoplankton cell orientations and its link with larger scales dynamics. Technological advances are also needed in order to intensify in situ observations.

Finally, we still need further understanding and full integration into mainstream biological oceanography of the governing laws and detailed mechanisms ruling in this microscale kingdom.

\section{AUTHOR CONTRIBUTIONS}

GB, JF-M, and IT conceived and wrote the manuscript.

\section{FUNDING}

This work was partially funded by the SIFOMED grant (CTM2017-83774-P) and INTERDIBIO (FIS2016-77692-C2-1P) from Ministerio de Ciencia, Innovación y Universidades (MICINN), the Agencia Estatal de Investigación (AEI) and the Fondo Europeo de Desarrollo Regional (FEDER, UE). This work benefited from the French state aid managed by the National Research Agency under the ISblue program (ANR-17-EURE0015).

Breier, R. E., Lalescu, C. C., Waas, D., Wilczek, M., and Mazza, M. G. (2018). Emergence of phytoplankton patchiness at small scales in mild turbulence. Proc. Natl. Acad. Sci. U.S.A. 115, 12112-12117. doi: 10.1073/pnas.1808711115

Bukatin, A., Kukhtevich, I., Stoop, N., Dunkel, J., and Kantsler, V. (2015). Bimodal rheotactic behavior reflects flagellar beat asymmetry in human sperm cells. Proc. Natl. Acad. Sci. U.S.A. 112, 15904-15909. doi: 10.1073/pnas.1515159112

Burd, A. B., and Jackson, G. A. (2009). Particle aggregation. Annu. Rev. Mar. Sci. 1, 65-90.

Cassie, R. M. (1959). Micro-distribution of plankton. N. Z. J. Sci. 2, 398-409.

Cassie, R. M. (1963). Microdistribution of plankton. Oceanogr. Mar. Biol. Ann. Rev. 1, 223-252.

Cowles, T. J., Desiderio, R. A., and Carr, M. E. (1998). Small-scale planktonic structure: persistence and trophic consequences. Oceanography 11, 4-9. doi: 10.5670/oceanog.1998.08

Cullen, J. J., and Horrigan, S. G. (1981). Effects of nitrate on the diurnal vertical migration, carbon to nitrogen ratio, and the photosynthetic capacity of the dinoflagellate Gymnodinium splendens. Mar. Biol. 62, 81-89. doi: 10.1007/ bf00388169

Currie, W. J. S., and Roff, J. C. (2006). Plankton are not passive tracers: plankton in a turbulent environment. J. Geophys. Res. 111:C05S07.

Dekshenieks, M. M., Donaghay, P. L., Sullivan, J. M., Rines, J. E. B., Osborn, T. R., and Twardowski, M. S. (2001). Temporal and spatial occurrence of thin phytoplankton layers in relation to physical processes. Mar. Ecol. Prog. Ser. 223, 61-71. doi: 10.3354/meps223061

Denman, K. L., and Platt, T. (1976). The variance spectrum of phytoplankton in a turbulent ocean. J. Mar. Res. 34, 593-601.

Denny, M. W. (1993). Air and Water: The Biology and Physics of Life's Media. Princeton, NJ: Princeton University Press. 
Derenbach, J. B., Astheimer, H., Hansen, H. P., and Leach, H. (1979). Vertical microscale distribution of phytoplankton in relation to the thermocline. Mar. Ecol. Prog. Ser. 1, 187-193. doi: 10.3354/meps001187

Doubell, M. J., Prairie, J. C., and Yamazaki, H. (2014). Millimeter scale profiles of chlorophyll fluorescence: deciphering the microscale spatial structure of phytoplankton. Deep-Sea Res. II 101, 207-205.

Durham, W., Climent, E., Barry, M., De Lillo, F., Boffetta, G., Cencini, M., et al. (2013). Turbulence drives microscale patches of motile phytoplankton. Nat. Commun. 4:2148.

Durham, W., Kessler, J. O., and Stocker, R. (2009). Disruption of vertical motility by shear triggers formation of thin phytoplankton layers. Science 323, 1067-1070. doi: $10.1126 /$ science. 1167334

Durham, W. M., Climent, E., and Stocker, R. (2011). Gyrotaxis in a steady vortical flow. Phys. Rev. Lett. 106:238102.

Durham, W. M., and Stocker, R. (2012). Thin phytoplankton layers: characteristics, mechanisms, and consequences. Ann. Rev. Mar. Sci. 4, 177-207. doi: 10.1146/ annurev-marine-120710-100957

Eppley, R. W., Holm-Harisen, O., and Strickland, J. D. H. (1968). Some observations of the vertical migration of marine dinoflagellates. J. Phycol. 4, 333-340.

Fenchel, T. (1993). There are more small than large species? Oikos 68, 375-378.

Font-Muñoz, J. S., Jeanneret, R., Arrieta, J., Anglès, S., Jordi, A., Tuval, I., et al. (2019). Collective sinking promotes selective cell pairing in planktonic pennate diatoms. Proc. Natl. Acad. Sci. U.S.A. 116, 15997-16002. doi: 10.1073/pnas. 1904837116

Goessling, J. W., Su, Y., Maibohm, C., Ellegaard, M., and Kühl, M. (2018). Differences in the optical properties of valve and girdle band in a centric diatom. Interface Focus 9, 20180031. doi: 10.1098/rsfs.2018.0031

Grant, H., Stewart, R., and Moilliet, A. (1962). Turbulence spectra from a tidal channel. J. Fluid Mech. 12, 241-268.

Gregg, M. C. (1980). Microstructure patches in the thermocline. Journal of Physical Oceanography 10, 915-943. doi: 10.1175/1520-0485(1980)010<0915:mpitt $>2.0$. $\mathrm{co} ; 2$

Gross, F., and Zheuten, E. (1948). The buoyancy of plankton diatoms: a problem of cell physiology. Proc. R. Soc. Lond. B 135, 382-389. doi: 10.1098/rspb.1948.0017

Guasto, J. S., Rusconi, R., and Stocker, R. (2012). Fluid mechanics of planktonic microorganisms. Annu. Rev. Fluid Mech. 44, 373e400.

Haeckel, E. (1891). Plankton studien. Jena Z. Naturwis. 25, 232-336.

Hall, N. S., and Paerl, H. W. (2011). Vertical migration patterns of phytoflagellates in relation to light and nutrient availability in a shallow microtidal estuary. Mar. Ecol. Prog. Ser. 425, 1-19. doi: 10.3354/meps09031

Harvey, H. W. (1942). Production of life in the sea. Biol. Rev. 17, 221-246. doi: 10.1111/j.1469-185x.1942.tb00438.x

Haury, L. R., McGowan, J. A., and Wiebe, P. H. (1978). "Patterns and processes in the time-space scales of plankton distribution," in Spatial Pattern in Plankton Communities, ed. J. H. Steele (New York, NY: Plenum Press), 277-327. doi: 10.1007/978-1-4899-2195-6_12

Hensen, V. (1887). "Über die bestimmung des plankton's oder des im meere treibenden materials an pflanzen und thieren," in Berichte Kommss. wissenschaftlichen Untersuchung der deutschen Meere eds Schmidt and Klaunig (Kiel: Berlin Parey) 5, 1-107.

Holling, C. S. (1992). Cross-scale morphology, geometry, and dynamics of ecosystems. Ecol. Monogr. 62, 447-502. doi: 10.2307/2937313

Holwill, M. E. J. (1974). "Hydrodynamic aspects of ciliary and flagellar movement," in Cilia and Flagella, ed. M. A. Sleigh (London: Academic Press), 43.

Jeffery, G. B. (1922). The motion of ellipsoidal particles immersed in a viscous fluid. Proc. R. Soc. Lond. A. 102, 161-179. doi: 10.1098/rspa.1922. 0078

Jeong, H. J., Lim, A. S., Franks, P. J. S., Lee, K. H., Kim, J. H., Kang, N. S., et al. (2015). A hierarchy of conceptual models of red-tide generation: nutrition, behavior, and biological interactions. Harmful Algae 47, 97-115. doi: 10.1016/j. hal.2015.06.004

Jumars, P. A., Trowbridge, J. H., Boss, E., and Karp-Boss, L. (2009). Turbulenceplankton interactions: a new cartoon. Mar. Ecol. 30, 133-150. doi: 10.1111/j. 1439-0485.2009.00288.x

Karp-Boss, L., Boss, E., and Jumars, P. A. (1996). Nutrient fluxes to planktonic osmotrophs in the presence of fluid motion. Oceanogr. Mar. Biol. Annu. Rev. 34, 71-107.
Karp-Boss, L., Boss, E., and Jumars, P. A. (2000). Motion of dinoflagellates in a simple shear flow. Limnol. Oceanogr. 45, 1594-1602. doi: 10.4319/lo.2000.45.7. 1594

Karp-Boss, L., and Jumars, P. A. (1998). Motion of diatom chains in steady shear flow. Limnol. Oceanogr. 43, 1767-1773. doi: 10.4319/lo.1998.43.8.1767

Kessler, J. O. (1985). Hydrodynamic focusing of motile algal cells. Nature 313, 218-220. doi: 10.1038/313218a0

Kiørboe, T. (1993). Turbulence, phytoplankton cell size, and the structure of pelagic food webs. Adv. Mar. Biol. 29, 1-72. doi: 10.1016/s0065-2881(08)60 129-7

Kiørboe, T. A. (2008). Mechanistic Approach to Plankton Ecology. Princeton, NJ: Princeton University Press.

Koch, D. L., and Shaqfeh, E. S. G. (1989). The instability of a dispersion of sedimenting spheroids. J. Fluid Mech. 209, 521-542. doi: 10.1017/ s0022112089003204

Kolmogorov, A. N. (1941). The local structure of turbulence in incompressible viscous fluid for very large Reynolds numbers. Dokl. Akad. Nauk SSSR 30, 301-305.

Kolmogorov, A. N. (1962). A refinement of previous hypotheses concerning the local structure of turbulence in a viscous incompressible fluid at high Reynolds number. J. Fluid Mech. 13, 82-85. doi: 10.1017/s0022112062000518

Lehman, J. T., and Scavia, D. (1982). Microscale patchiness of nutrients in plankton communities. Science 216, 729-730. doi: 10.1126/science.216.4547.729

Levich, V. G. (1962). Physicochemical Hydrodynamics. Upper Saddle River, NJ: Prentice Hall, 163.

Levin, S. A. (1992). The problem of pattern and scale in ecology. Ecology 73, 1943-1967. doi: 10.2307/1941447

Lighthill, J. (1976). Flagellar hydrodynamics. SIAM Rev. 18, 161-230. doi: 10.1137/ 1018040

Lorenzen, C. J. (1966). A method for the continuous measurement of in rive chlorophyll concentration. Deep-Sea Res. 13, 223-227. doi: 10.1016/00117471(66)91102-8

Lovecchio, S., Climent, E., Stocker, R., and Durham, W. M. (2019). Chain formation can enhance the vertical migration of phytoplankton through turbulence. Sci. Adv. 5:EAAW7879.

Marcos, Fu, H. C., Powers, T. R., and Stocker, R. (2012). Bacterial rheotaxis. Proc. Natl. Acad. Sci. U.S.A. 109, 4780-4785. doi: 10.1073/pnas.1120955109

Marcos, Seymour, J. R., Luhar, M., Durham, W. M., Mitchell, J. G., Macke, A., et al. (2011). Microbial alignment in flow changes ocean light climate. Proc. Natl. Acad. Sci. U.S.A. 108, 3860-3864. doi: 10.1073/pnas.1014576108

Margalef, R. M. (1967). Some concepts relative to the organization of plankton. Oceanogr. Mar. Biol. Ann. Rev. 5, 257-289.

Margalef, R. M. (1978). Life forms of phytoplankton as survival alternatives in an unstable environment. Oceanol. Acta 1, 493-509.

Mathijssen, A. J. T. M., Figueroa-Morales, N., Junot, G., Clément, E., Lindner, A., and Zöttl, A. (2019). Oscillatory surface rheotaxis of swimming E. coli bacteria. Nat. Commun. 10:3434.

Metzger, B., Guazzelli, E., and Butler, J. E. (2005). Large-scale streamers in the sedimentation of a dilute fiber suspension. Phys. Rev. Lett. 95:164506.

Nayak, A. R., McFarland, M. N., Sullivan, J. M., and Twardowski, M. S. (2018). Evidence for ubiquitous preferential particle orientation in representative oceanic shear flows. Limnol. Oceanogr. 63, 122-143. doi: 10.1002/lno.10618

Owen, R. W. (1989). Microscale and finescale variations of small plankton in coastal and pelagic environments. J. Mar. Res. 47, 197-240. doi: 10.1357/ 002224089785076415

Passow, U. (2002). Transparent exopolymer particles (TEP) in aquatic environments. Prog. Oceanogr. 55, 287-333. doi: 10.1016/s0079-6611(02) 00138-6

Pedley, T. J., and Kessler, J. O. (1992). Hydrodynamic phenomena in suspensions of swimming microorganisms. Annu. Rev. Fluid Mech. 24, 313-358. doi: 10.1146/ annurev.fl.24.010192.001525

Platt, T. (1972). Local phytoplankton abundance and turbulence. Deep-Sea Res. 19, 183-187. doi: 10.1016/0011-7471(72)90029-0

Platt, T. (1978). "Spectral analysis of spatial structure in phytoplankton populations," in Spatial Patterns in Plankton Communities, ed. J. H. Steele (Brussels: NATO conference Series), 73-84. doi: 10.1007/978-1-4899-2195-6_4 Powell, T. M., Richardson, P. J., Dillon, T. M., Agee, B. A., Dozier, B. J., Godden, D. A., et al. (1975). Spatial scales of current speed and phytoplankton biomass 
fluctuations in Lake Tahoe. Science 189, 1088-1090. doi: 10.1126/science.189. 4208.1088

Prairie, J. C., Sutherland, K. R., Nickols, K. J., and Kaltenberg, A. M. (2012). Biophysical interactions in the plankton: a cross-scale review. Limnol. Oceanogr. Fluids Environ. 2, 121-145. doi: 10.1215/21573689-1964713

Purcell, E. M. (1977). Life at low Reynolds number. Am. J. Phys. 45, 3-11.

Reynolds, C. S. (1997). Vegetation Processes in the Pelagic: A Model for Ecosystem Theory. xxvii, Oldendorf/Luhe. Berlin: Ecology Institute, 371.

Reynolds, C. S. (2006). The Ecology of Phytoplankton. Cambridge: Cambridge University Press.

Rietkerk, M., Dekker, S. C., de Ruiter, P. C., and van de Koppel, J. (2004). Self-organized patchiness and catastrophic shifts in ecosystems. Science 305, 1926-1929. doi: 10.1126/science.1101867

Riley, G. A. (1942). The relationship of vertical turbulence and spring diatom flowering. J. Mar. Res. 5, 67-87.

Riley, G. A., Stommel, H. M., and Bumpus, D. (1949). Quantitative ecology of the plankton of the Western North Atlantic. B. Bingham Oceanogr. C. 12, 1-169.

Rothschild, B. J., and Osborn, T. R. (1988). Small-scale turbulence and plankton contact rates. J. Plankton Res. 10, 465-474. doi: 10.1093/plankt/10.3.465

Ruiz, J., Maciìs, D., and Peters, F. (2004). Turbulence increases the average settling velocity of phytoplankton cells. Proc. Natl. Acad. Sci. U.S.A. 101, 17720-17724. doi: 10.1073/pnas.0401539101

Rusconi, R., Guasto, J. S., and Stocker, R. (2014). Bacterial transport is suppressed by fluid shear. Nat. Phys. 10, 212-217. doi: 10.1038/nphys 2883

Russel, F. S. (1950). Quantitative ecology of plankton. Nature 165, 559-560. doi: 10.1038/165559a0

Sachs, J. (1876). Ueber Emulsionsfiguren und Gruppirung der Schwarmsporen im Wasser. Flora 59, 273-275.

Schofield, O., Kerfoot, J., Mahoney, K., Moline, M., Oliver, M., Lohrenz, S., et al. (2006). Vertical migration of the toxic dinoflagellate Karenia brevis and the impact on ocean optical properties. J. Geophys. Res. Oceans 111:C06009.

Schwarz, F. (1884). Der einfluss der schwerkraft auf die bewegungsrichtung von chlamidomonas und euglena ber. Deutsch. Bot. Ges. 2, 51-72.

Seymour, J. R., Simó, R., Ahmed, T., and Stocker, R. (2010). Chemoattraction to dimethyl-sulfoniopropionate throughout the marine microbial food web. Science 329, 342-345. doi: 10.1126/science. 1188418

Sheldon, R. W., Prakash, A., and Sutcliffe, W. H. Jr. (1972). The size distribution of particles in the ocean. Limnol. and Oceanogr. 17, 327-340. doi: 10.4319/lo.1972. 17.3.0327

Siegel, D. A. (1998). Resource competition in a discrete environment: why are plankton distributions paradoxical? Limnol. Oceanogr. 43, 1133-1146. doi: 10. 4319/lo.1998.43.6.1133

Smayda, T. J. (1980). "Phytoplankton species succession," in The Physiological Ecology of Phytoplankton, ed. I. Morris (Oxford: Blackwell Scientific Publications), 493-570.
Sournia, A. (1982). Form and function in marine phytoplankton. Biol. Rev. 57, 347-394. doi: 10.1111/j.1469-185x.1982.tb00702.x

Steele, J. H. (1959). The quantitative ecology of marine phytoplankton. Biol. Rev. 34, 129-158. doi: 10.1111/j.1469-185x.1959.tb01287.x

Steele, J. H. (1978). Spatial Pattern in Plankton Communities. Plenum Press, NY: NATO Conference Series. IV.

Stocker, R. (2012). Marine microbes see a sea of gradients. Science 338, 628-633. doi: 10.1126/science. 1208929

Stocker, R., Seymour, J. R., Samadani, A., Hunt, D. E., and Polz, M. F. (2008). Rapid chemotactic response enables marine bacteria to exploit ephemeral microscale nutrient patches. Proc. Natl. Acad. Sci. U.S.A. 105, 4209-4214. doi: 10.1073/ pnas.0709765105

Stommel, H. (1963). Varieties of oceanographic experience. Science 139, 572-576. doi: $10.1126 /$ science.139.3555.572

Sverdrup, H. U. (1953). On conditions for the vernal blooming of phytoplankton. ICES J. Mar. Sci. 18, 287-295. doi: 10.1093/icesjms/18.3.287

Talapatra, S., Hong, J., McFarland, M., Nayak, A. R., Zhang, C., Katz, J., et al. (2013). Characterization of biophysical interactions in the water column using in situ digital holography. Mar. Ecol. Prog. Ser. 473, 29-51. doi: 10.3354/meps10049

Uppal, G., and Vural, D. C. (2018). Shearing in flow environment promotes evolution of social behavior in microbial populations. eLife 7:e34862.

Vance, T. C., and Doel, R. E. (2010). Graphical methods and cold war scientific practice: the stommel diagram's intriguing journey from the physical to the biological environmental sciences. Hist. Stud. Nat. Sci. 40, 1-47. doi: 10.1525/ hsns.2010.40.1.1

Voth, G. A., and Soldati, A. (2017). Anisotropic Particles in Turbulence. Annu. Rev. Fluid Mech. 49, 249-276. doi: 10.1146/annurev-fluid-010816-060135

Wager, H. W. T. (1910). The effect of gravity upon the movements and aggregation of euglena viridis, ehrb., and other micro-organisms. Proc. R. Soc. Lond. B. 83.

Walsby, A. E. (1994). Gas vesicles. Microbiol. Rev. 58, 94-144. doi: 10.1128/mmbr. 58.1.94-144.1994

Wheeler, J. D., Secchi, E., Rusconi, R., and Stocker, R. (2019). Not just going with the flow: the effects of fluid flow on bacteria and plankton. Annu. Rev. Cell Dev. Biol. 35, 213-237. doi: 10.1146/annurev-cellbio-100818-125119

Conflict of Interest: The authors declare that the research was conducted in the absence of any commercial or financial relationships that could be construed as a potential conflict of interest.

Copyright (c) 2020 Basterretxea, Font-Muñoz and Tuval. This is an open-access article distributed under the terms of the Creative Commons Attribution License (CC BY). The use, distribution or reproduction in other forums is permitted, provided the original author(s) and the copyright owner(s) are credited and that the original publication in this journal is cited, in accordance with accepted academic practice. No use, distribution or reproduction is permitted which does not comply with these terms. 